\title{
A Crustal Velocity Model for the Southern Mexicali Valley, Baja California, Mexico
}

\section{by Erik E. Ramírez-Ramos, Antonio Vidal-Villegas, Antonio González-Fernández, and Joann M. Stock}

\section{INTRODUCTION}

In northern Baja California, the two largest regions with different geological characteristics are the granitic Peninsular Ranges of Baja California (PRBC) and the sedimentary environment of the Mexicali Valley (Lomnitz et al., 1970). The boundary of these two regions is the Main Gulf Escarpment (Fig. 1). The northern Baja California peninsula has active normal and strike-slip faults originating from the transtensional limit between the Pacific and North America plates (Stock et al., 1991). In this limit, separation of the Baja California peninsula from the continental North America plate occurs and continues to the northwest through the right-lateral movement (Fig. 1 inset) of the San Andreas fault system (Axen and Fletcher, 1998; Suárez-Vidal et al., 2007; Plattner et al., 2007; Suárez-Vidal et al., 2008; Armstrong, 2010; Wei et al., 2011; Oskin et al., 2012). Within our study area (Fig. 1), south of Mexicali Valley, the Cucapah and El Mayor mountain ranges are located northwest of the Gulf Extensional Province (Suárez-Vidal, et al. 2008). These two mountain ranges are the result of the uplift of Mesozoic basement flanked by active faults: Laguna Salada and Cañada David detachment faults (Spelz-Madero et al. 2008), with the Laguna Salada basin to the west and the Mexicali Valley basin to the east. Both faults dip west and have accommodated $>10 \mathrm{~km}$ of offset since the middle-late Miocene (Fletcher and Spelz, 2009). The Laguna Salada is a tectonic basin $20 \mathrm{~km}$ wide by $100 \mathrm{~km}$ long in a north-northwest direction (García-Abdeslem et al., 2001). It is bounded on the west by the Gulf escarpment (Angelier et al., 1981; Henry, 1989) and on the east by the Cucapah and El Mayor Mountains. According to García-Abdeslem et al. (2001), the thickness of the sedimentary blanket in the Laguna Salada basin increases eastward, reaching a maximum depth of $3 \mathrm{~km}$. Sedimentation began during the Pleistocene when uplift of the Cucapah and El Mayor mountain ranges cut off this region from the Colorado River delta (Martín-Barajas et al., 2001; Contreras et al., 2005). The Mexicali Valley basin is located to the east of the Cucapah and El Mayor Mountains. Tertiary and recent sediments of this basin are around 5-6 km thick (Pelayo et al., 1991). These sediments, like those of the Laguna Salada basin, were transported by the Colorado River. Within this basin, southeast of the Cucapah Mountains and northeast of the El Mayor Mountains, is located the epicenter of the $M_{\mathrm{w}} 7.2 \mathrm{El}$ Mayor-Cucapah earthquake (of 4 April 2010). Although many faults ruptured within the mountains and near Laguna Salada due to this earthquake (Fletcher et al., 2014), it was shown by analysis of Advanced Land Observing Satellite Phased Array type L-band Synthetic Aperture Radar (ALOS PALSAR) and Landsat imagery that the Indiviso fault, a previously unknown fault east of the El Mayor Mountain within Mexicali Valley, also ruptured because of this earthquake (González-García et al., 2010).

Because of the importance of the tectonic environment of northern Baja California, and the occurrence of the recent $M_{\mathrm{w}} 7.2 \mathrm{El}$ Mayor-Cucapah earthquake, it is necessary to have a velocity structure model as detailed as possible for the southern Mexicali Valley. To determine this model, a refraction study was carried out. This study is composed of a $125 \mathrm{~km}$ length profile that starts at San Luis Rio Colorado, Sonora, Mexico, continues southwest through the southern Mexicali Valley, crosses south of Laguna Salada, and ends in the central Sierra Juárez Mountains (Fig. 1). The aim of this study is to determine a $P$-wave velocity model for the crust and upper mantle beneath the south Mexicali Valley that could be used, for instance, in the location of earthquakes of the region. At present, for location of these earthquakes, the Mexicali Valley model (MVM) is used. Fabriol and Munguía (1995) obtained this model from one proposed by McMechan and Mooney (1980) for Imperial Valley, California.

\section{INSTRUMENTATION AND DATA}

\section{Recording}

Temporary instruments installed along the refraction profile included 16 three-component short-period stations (Geospace Technologies HS-1 [2 Hz] seismometers, with 24-bit SARA recorders SL06), and one broadband station (Geotech seismometer KS-200 [100 s-50 Hz] with 24-bit REF TEK DAS-130 recorder). In this refraction profile, we also included a three-component short-period station (Mark L4-C [1 Hz] seismometer and an in-house-designed 12-bit recorder) belonging to the Red Sísmica del Noroeste de México (RESNOM); this station, station SLX, is located at San Luis Rio Colorado, Sonora (SLRC). Spacing between stations in the profile was $\sim 6 \mathrm{~km}$, and they operated from 2 to 15 March 2011 (Table 1). Stations recorded in continuous mode at either 100 or 40 samples per second (for the short-period temporary stations and the broadband temporary station and for the short-period SLX station, respectively). The blast (direct shot), composed 
(b)

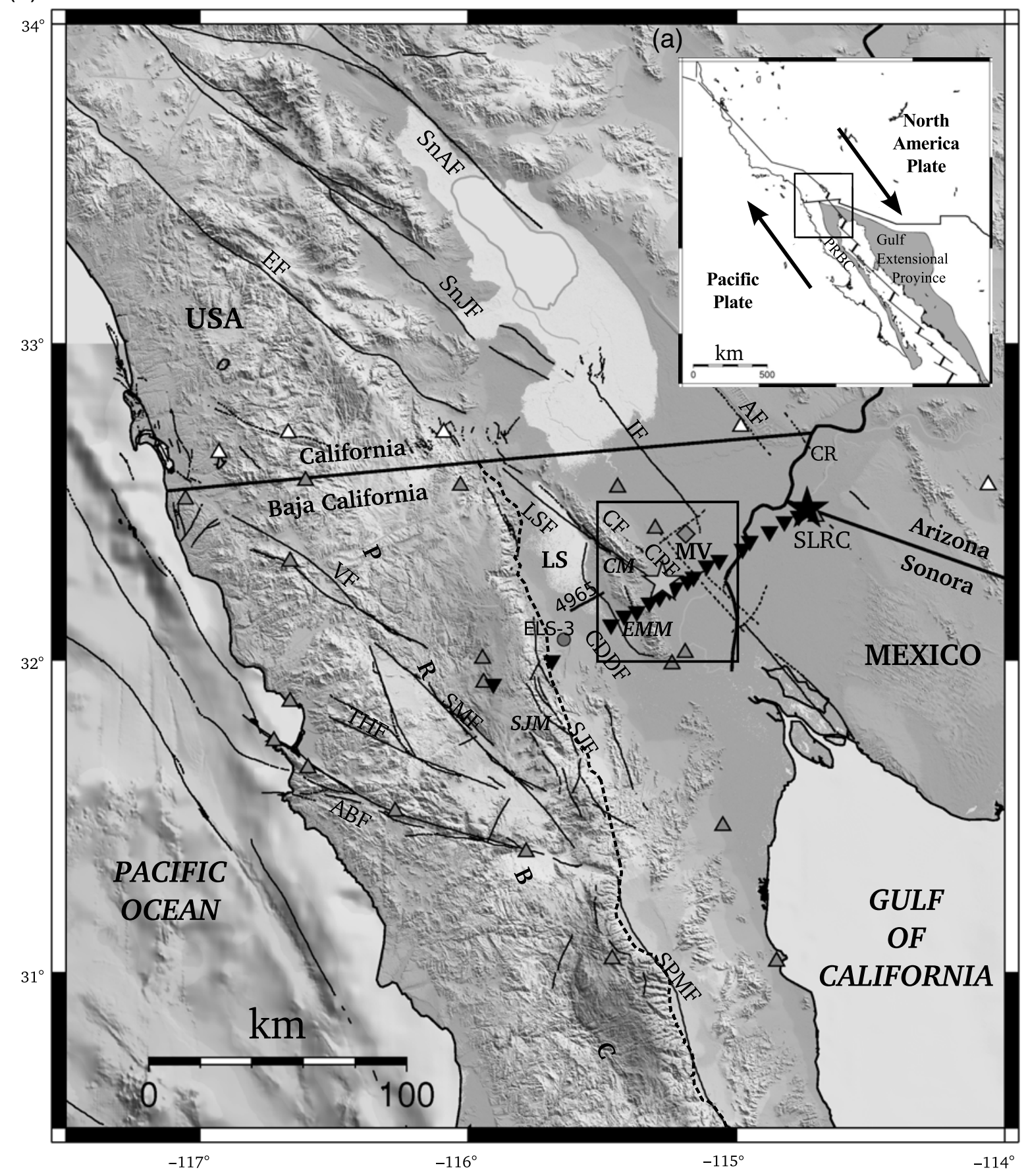

A Figure 1. The two main geological provinces of northwestern Mexico and (inset) the global context of the boundary and the interaction of the North American and Pacific plates. The detailed map shows the main faults of the northern Baja California and southern California regions and the locations of the direct (Arizona) and reversed (northeast of El Mayor) shots (black and gray stars, respectively). The temporary stations (inverted black triangles) of the refraction profile and some stations (gray and white triangles, gray diamond) of permanent networks that operate in the region are also shown. The dashed black line represents the limit of the Main Gulf Escarpment in northern Baja California. The zone marked by a rectangle on the map is shown in Figure 2. (1) Regions or sites: PRBC, Peninsular Ranges of Baja California; MV, Mexicali Valley; LS, Laguna Salada; SLRC, San Luis Río Colorado; EMM, El Mayor Mountains; CM, Cucapah Mountains; SJM, Sierra Juárez Mountains. (2) Faults: SPMF, San Pedro Mártir fault; ABF, Agua Blanca fault; THF, Tres Hermanos fault; SMF, San Miguel fault; VF, Vallecitos fault; SJF, Sierra Juárez fault; CDDF, Cañada David detachment fault; LSF, Laguna Salada fault; CF, Cucapah fault; CPF, Cerro Prieto fault; IF, Imperial fault; AF, Algodones fault; SnAF, San Andreas fault; SnJF, San Jacinto fault; EF, Elsinore fault. The locations of the plotted faults were obtained from Seiler et al. (2010). (3) Supplement data: the reflection profile (4965) is from Gallardo-Mata (2013; black line); the location of well log ELS-3 is from Martín-Barajas et al. (2001; gray circle). 


\begin{tabular}{|c|c|c|c|c|}
\hline \multicolumn{5}{|c|}{$\begin{array}{c}\text { Table } 1 \\
\text { Coordinates of Stations and Station-Blast Distance in the } \\
\text { Refraction Profile }\end{array}$} \\
\hline Station & $\begin{array}{c}\text { Latitude } \\
\left({ }^{\circ}\right) \\
\end{array}$ & $\begin{array}{c}\text { Longitude } \\
\left({ }^{\circ}\right) \\
\end{array}$ & $\begin{array}{c}\text { Elevation } \\
(\mathrm{m})\end{array}$ & $\begin{array}{c}\text { Distance } \\
(\mathbf{k m})\end{array}$ \\
\hline SLX & 32.4571 & -144.7683 & 49 & 4.14 \\
\hline 142 & 32.4401 & -114.8229 & 25 & 9.18 \\
\hline 156 & 32.4081 & -114.8786 & 25 & 15.49 \\
\hline 133 & 32.3784 & -114.9517 & 32 & 23.09 \\
\hline 132 & 32.3522 & -114.9788 & 21 & 26.77 \\
\hline 137 & 32.3172 & -115.0643 & 20 & 35.67 \\
\hline 145 & 32.2999 & -115.1119 & 17 & 40.5 \\
\hline 128 & 32.2644 & -115.1603 & 16 & 46.43 \\
\hline 138 & 32.2501 & -115.1823 & 13 & 49.02 \\
\hline 157 & 32.2301 & -115.2286 & 15 & 53.91 \\
\hline 149 & 32.2202 & -115.2497 & 7 & 56.18 \\
\hline 144 & 32.2000 & -115.2880 & 8.6 & 60.43 \\
\hline 152 & 32.1818 & -115.3244 & 3.2 & 64.41 \\
\hline 140 & 32.1546 & -115.3714 & 70.8 & 69.76 \\
\hline 153 & 32.1414 & -115.4196 & 4.5 & 74.42 \\
\hline 147 & 32.1134 & -115.4681 & 5.8 & 79.93 \\
\hline 148 & 31.9980 & -115.6874 & 270 & 104.28 \\
\hline 200 & 31.9246 & -115.9073 & 1664 & 126.33 \\
\hline
\end{tabular}

of $1440 \mathrm{~kg}$ of explosives at $40 \mathrm{~m}$ depth, was detonated in southwestern Arizona (Fig 1). The deployed seismic stations recorded this explosion as part of the Salton Seismic Imaging Project (Rose et al., 2013). Because of the absence of a reversed explosion, we searched for an earthquake in the RESNOM database that occurred at the southwest end of the profile and was recorded by the stations of the profile. An M 3.4 aftershock of the $M_{\mathrm{w}} 7.2$ El Mayor-Cucapah earthquake was found as the best candidate to be used as a reversed shot. We selected this earthquake because the RESNOM agency reported the epicenter close to the profile. However, this earthquake is not at the end of the profile, but rather is located near the middle, at $9.9 \mathrm{~km}$ depth (east of the El Mayor Mountain and at $\sim 5 \mathrm{~km}$ distance from the profile; Fig. 2a); thus, only the eastern half of the profile is reversed. Regarding the depth of the earthquake, we calculated it using the velocity model reported by Castro $e t$ al. (2011). Details of the relocation process are discussed next.

\section{Reduction}

Raw data from the explosion and the selected earthquake were extracted from the recorders and converted to SeisAn format (Havskov and Ottemöller, 1999; Ottemöller and Havskov, 1999). We created a database with seismograms of temporary stations along with those gathered by RESNOM stations. We preferred not to apply any filter or instrument correction. In the first case, the $P$ arrivals were so clear (good signal-to-noise ratio); and, in the second case, we worked with relative amplitudes (scaled to the maximum value). In addition, the frequency response of the instruments that we used is linear in the fre- (a)

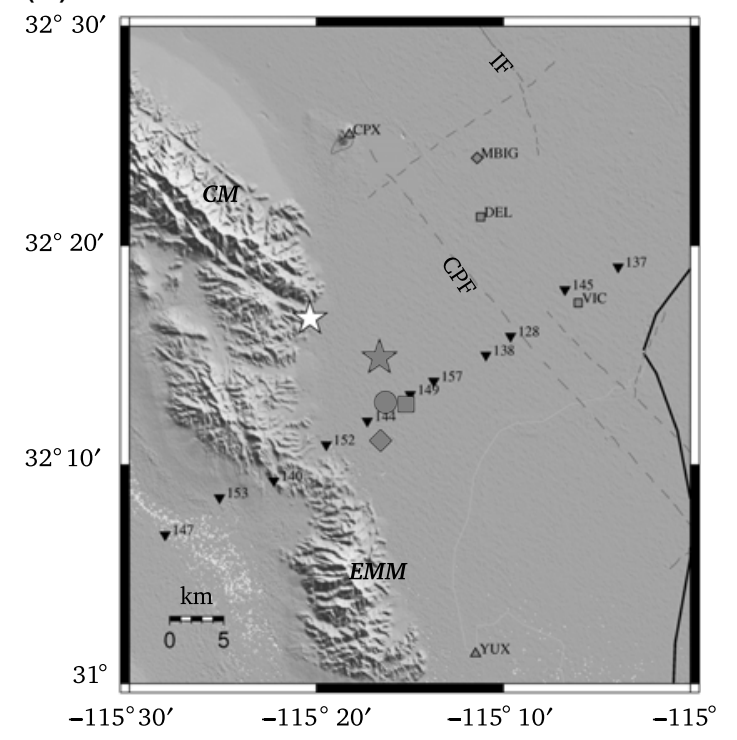

(b)

(c)

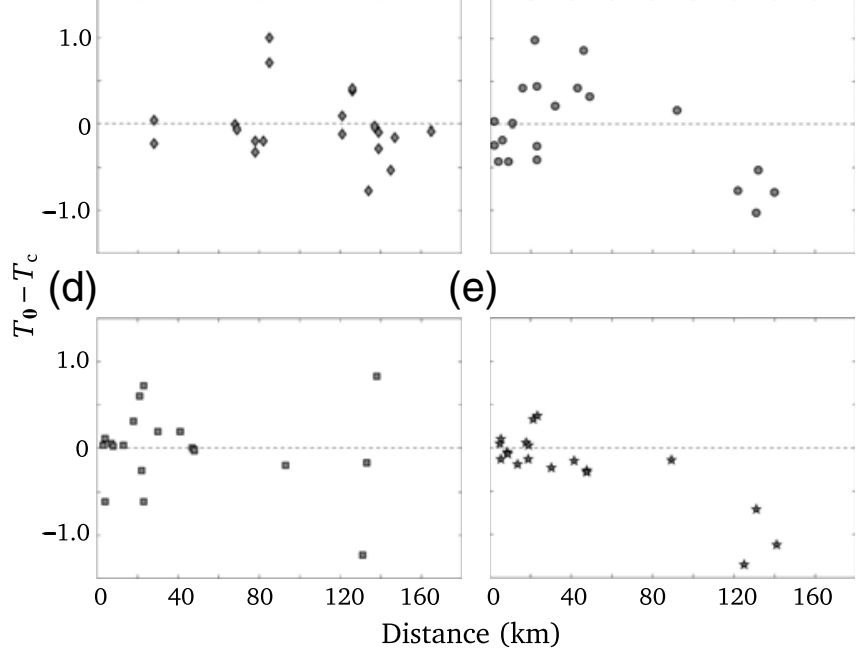

- Figure 2. (a) Enlarged map of southern Mexicali Valley showing the epicenters obtained in the relocation of the earthquake used as the reversed shot. The permanent stations (gray triangles and squares, and gray diamond) and temporary stations (inverted black triangles [138-153 of the refraction profile]) used in this process are also shown. The white star indicates the location of the 4 April 2010 $M_{\mathrm{w}} 7.2 \mathrm{El}$ Mayor-Cucapah earthquake, and gray symbols are various relocations of the aftershock selected as the reversed source: the gray diamond (location reported by Red Sísmica del Noroeste de México [RESNOM]), gray square (relocation using the Mexicali Valley Model [MVM]), gray circle (relocation using the PRBCM), and gray star (relocation with the C11M). IF, Imperial fault; CPF, Cerro Prieto fault; CM, Cucapah Mountain; and EMM, El Mayor Mountain. (b-e) Plots of residual time differences (observed $\left[T_{0}\right]$ minus calculated $\left[T_{c}\right]$ ) versus distance of the stations used for the relocation of the reversed shot. Different plots show time residuals obtained with each of the following models: (b) location of RESNOM using the PRBCM; (c) PRBCM; (d) MVM; and (e) C11M. See Reduction section for details of the models. 


\begin{tabular}{|cccccc|}
\hline \multicolumn{7}{|c|}{ Table 2 } \\
Locations of the Earthquake Used as the Reverse Shot \\
\hline Model & $\begin{array}{c}\text { Origin Time } \\
\text { (hh:mm:ss.s) }\end{array}$ & $\begin{array}{c}\text { Latitude } \\
\left({ }^{\circ}\right)\end{array}$ & $\begin{array}{c}\text { Longitude } \\
\left({ }^{\circ}\right)\end{array}$ & $\begin{array}{c}\text { Depth } \\
(\mathbf{k m})\end{array}$ & rms \\
\hline C11M & $20: 26: 09.3$ & 32.2480 & -115.2770 & 9.9 & 0.17 \\
MVM & $20: 26: 08.6$ & 32.2128 & -115.2533 & 13.8 & 0.47 \\
PRBCM & $20: 26: 10.4$ & 32.2141 & -115.2716 & 12.8 & 0.52 \\
RESNOM & $20: 26: 09.7$ & 32.1698 & -115.2533 & $6.0^{*}$ & 0.39 \\
\hline These locations were obtained using four velocity models. \\
*Value fixed by the analyst. \\
\hline
\end{tabular}

quency range of our interest (greater than $\sim 1.8 \mathrm{~Hz}$ ). We relocated the selected earthquake, supplementing the arrival times of the RESNOM database with readings from the temporary stations and from some accelerograms recorded by stations of the Red de Acelerógrafos del Noroeste de México (RANM). Stations that provided data for the relocation process are shown in Figure 2a. For this process, we tested three crustal velocity models (1) the MVM, which is a seven-flat-layer model with a crustal thickness of $20 \mathrm{~km}$ and a $P$ velocity of $7.8 \mathrm{~km} / \mathrm{s}$ for the upper mantle; (2) the PRBC model (PRBCM) proposed by Nava and Brune (1982), which is a three-flat-layer model with a crustal thickness of $\sim 42 \mathrm{~km}$ and a $P$ velocity of $8.0 \mathrm{~km} / \mathrm{s}$ for the upper mantle; and (3) a modified version of the model by Fuis et al. (1984), derived from the profile 6NNW-13SSE and used by Castro et al. (2011; hereafter C11M). This last model, composed of 12 flat layers, has a crustal thickness of $40 \mathrm{~km}$ and a $P$ velocity of $8.0 \mathrm{~km} / \mathrm{s}$ for the upper mantle. The purpose of testing these models was to find the model that produced the best hypocentral location (time residual $<0.3 \mathrm{~s}$ ) for the selected earthquake. We compared our relocation results with the location reported by RESNOM. The time residuals obtained with the different models are shown in Figure 2b-e.

We selected the model that generates the smallest root mean square (rms; 0.17, Table 2) and least dispersion in the time residual against distance plot (Fig. 2e) after the relocation process. This model (C11M) was used by Castro et al. (2011) to locate hypocenters of the aftershocks of the El Mayor-Cucapah earthquake that occurred in the same area (south Mexicali Valley). The selected earthquake (Table 2) was located at $\sim 3.5 \mathrm{~km}$, perpendicular distance, north of the profile and $57 \mathrm{~km}$ southwest of the blast (northeast of El Mayor Mountain, Fig. 2a).

As part of the modeling process, we also included the topography (every $1 \mathrm{~km}$ ) to account for mountain ranges such as El Mayor (maximum elevation $700 \mathrm{~m}$ ) and Sierra Juárez (maximum elevation $2000 \mathrm{~m}$ ) that the profile crosses (Fig. 3a). In addition, it was important to locate the limits of the Mexicali Valley and the Laguna Salada basins where the basement crops out, to include them in the modeling process.

\section{INTERPRETED PHASES}

To correlate the distances and time arrivals to each station of the profile, we wrote a MATLAB (http://www.mathworks.com/

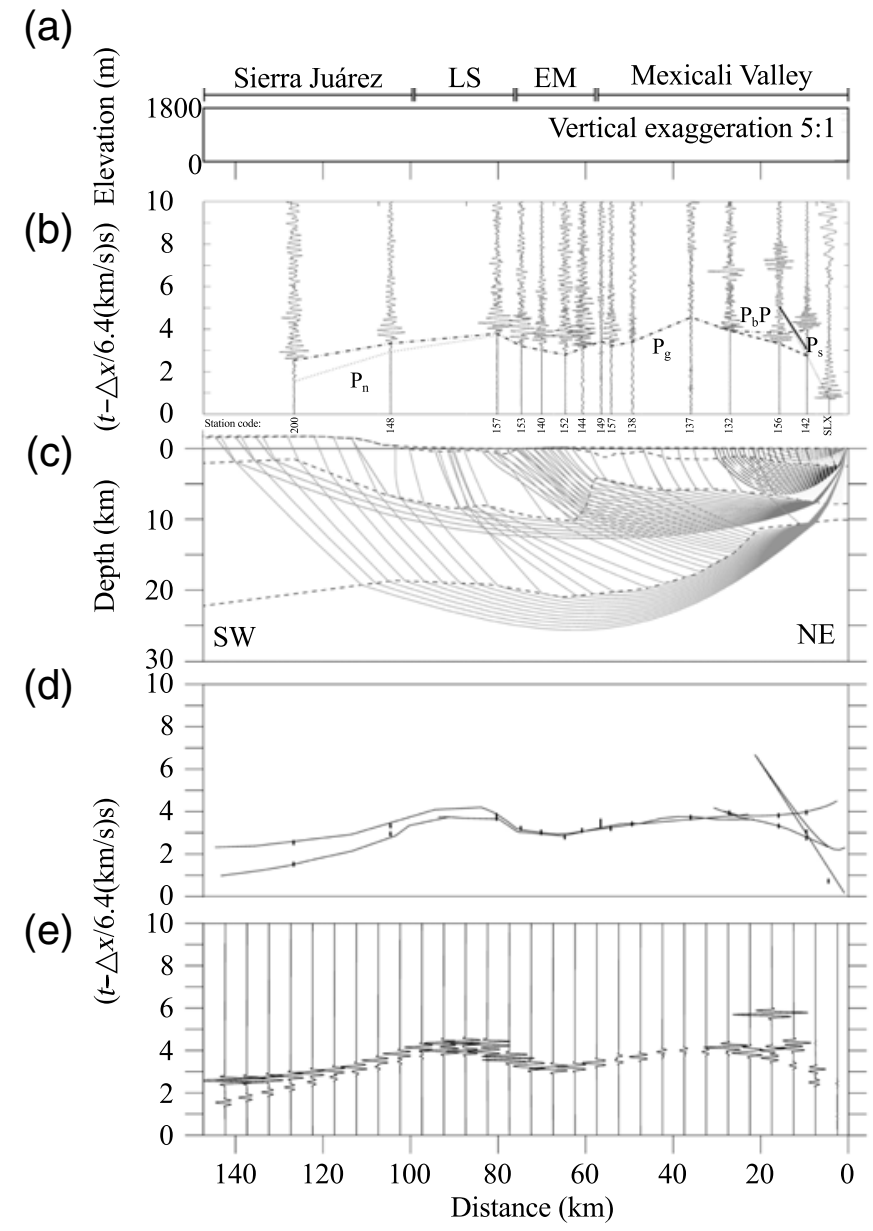

A Figure 3. Plots that illustrate the process of direct modeling of the observed seismograms, gathered from the direct shot, to obtain the synthetic seismograms. (a) Elevations along the profile (LS, Laguna Salada; EMM, El Mayor Mountain). (b) The record section for the direct shot with travel-time reduction. Interpreted phases: $P g$, direct $P$ wave; $P s$, direct $P$ wave through sediments; $P b P$, a reflected phase; and $P n, P$-wave refracted at the Moho. (c) Velocity model, including the ray tracing. (d) Record section of the direct shot with travel-time reduction. Interpreted phases: $P$, direct $P$ wave; $P$-wave $P m P$, reflected at the Moho. (e) Synthetic seismograms showing normalized amplitudes.

products/matlab/; last accessed October 2014) script to plot distance against reduced travel time for seismograms of the explosion and the earthquake. Figures $3 \mathrm{~b}$ and $4 \mathrm{~b}$ show record sections, composed of vertical-component seismograms, of stations that recorded the direct shot and the earthquake used as the reversed source, respectively. Two exceptions involve stations 137 and 149, for which the seismograms correspond to the east-west and north-south component, respectively. We used these components because the direct shot was not recorded on the vertical component. Both sections were plotted with a reduced velocity of $6.4 \mathrm{~km} / \mathrm{s}$ (average of $P$-wave crustal velocity in northern Baja California). Amplitudes in the seismograms were normalized to the maximum absolute amplitude of all traces. 
We interpreted the following phases of the direct shot (Fig. 3b):

- A direct $P$-wave phase ( $P s$ wave, traveling through sediments) from the shot point to $20 \mathrm{~km}$ distance. The apparent mean velocity of $P_{s}$ is $1.8 \mathrm{~km} / \mathrm{s}$, corresponding to a low-velocity layer in the Mexicali Valley basin. $P_{s}$ is represented by a dotted line in the first three seismograms: stations SLX, 142, and 156.

- A reflected phase is observed in the seismograms of stations 142 and 156 (continuous black line). This phase, denoted as $P b P$, travels with an apparent velocity of $4.5 \mathrm{~km} / \mathrm{s}$.

- The phase observed between the distances of $\sim 10-130 \mathrm{~km}$, marked as a dashed-dotted line in Figure $3 \mathrm{~b}$, is the $P g$ phase, which travels with an apparent velocity of $6.9 \mathrm{~km} / \mathrm{s}$.

- We identified the $P n$ phases in the three most distant traces $(\Delta x \geq 80 \mathrm{~km})$ from the explosion. The $P n$ arrivals, in the last three seismograms (stations 157-200), are indicated as a dotted line. This phase has a velocity of $7.7 \mathrm{~km} / \mathrm{s}$, corresponding to the mantle $P$-wave velocity.

Concerning the reversed source, Figure $4 \mathrm{~b}$ shows a record section of the vertical-component seismograms (reduced travel time against distance). In this figure, we identify the following features:

- the up-rising, impulsive, and high amplitude $P$ arrivals, which are linked with a dashed-dotted line, and

- a reflected PmP phase, which is indicated in the seismograms as a continuous line.

In the reversed source, the fact that it was not an explosion, but rather an earthquake, leads to uncertainty in the exact location and origin time of the source. Because of that, after the relocation of the earthquake and the modeling process, the origin time was adjusted by $+0.62 \mathrm{~s}$, and the depth by $+0.2 \mathrm{~km}$.

\section{MODELING TRAVEL TIMES AND AMPLITUDES}

\section{The Procedure}

From the interpreted phases, we modeled their travel times and their normalized amplitudes through the computation of synthetic seismograms. These seismograms were computed using asymptotic ray theory. We did this direct modeling using the program RAYGUI, developed at the U.S. Geological Survey by Song and ten Brink (2005). This program is a modified version of the RAYINVR program (Zelt and Smith, 1992), which works in a graphical environment. Modifying the parameterization of number, position, and velocity of boundary nodes allows direct modeling of the crustal velocity structure. Zelt and Ellis (1998) proposed this method to adjust the calculated time, which is obtained by forward ray tracing across the initial model. We considered an arrival time reading error of $\pm 0.01 \mathrm{~s}$ to be introduced in the RAYINVR program. The calculated time is then compared to the observed arrival time. For a layered structure, with variations in two dimensions, of depth and velocity, we also take into account the rms travel-time residuals to adjust the model.

We started modeling by adding layers with an arbitrary depth, except at the top of the first layer (on which we add the (a)

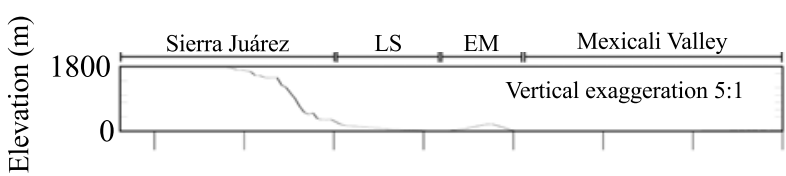

(b)

(c)

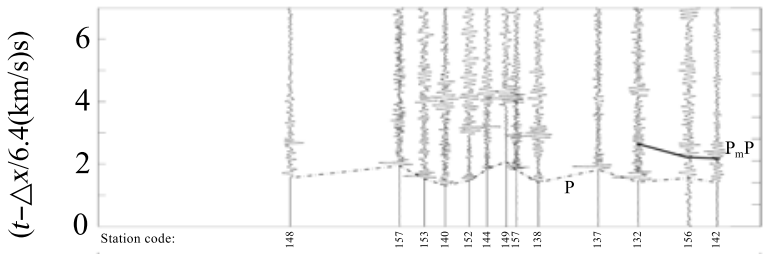

(d)

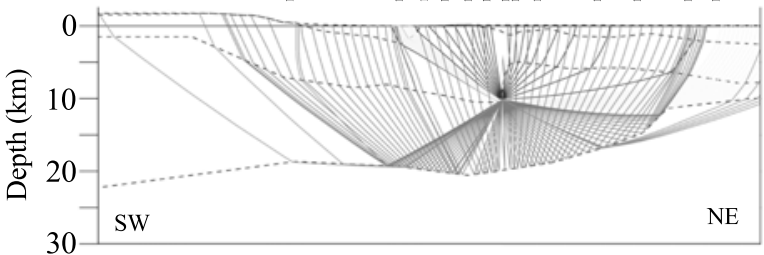

(e)

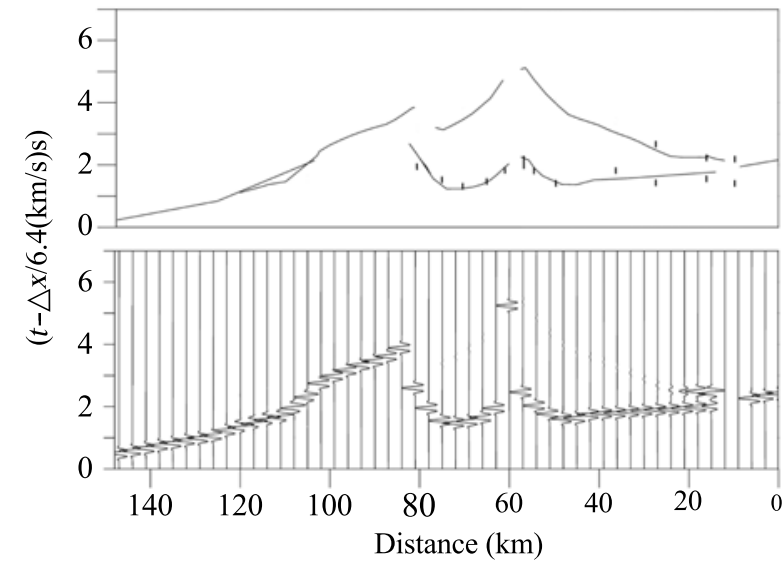

A Figure 4. Plots that illustrate the process of direct modeling of the observed seismograms, gathered from the earthquake used as reversed source, to obtain the synthetic seismograms. (a) Elevations along the profile (LS, Laguna Salada; EMM, El Mayor Mountain). (b) Record section for the reverse source with travel-time reduction. Interpreted phases: $P$, direct $P$ wave; $P m P, P$ wave reflected at the Moho. (c) Velocity model, including the ray tracing. (d) Adjusted travel times and readings of the interpreted phases. (e) Synthetic seismograms showing normalized amplitudes.

topography of the surface; Fig. 3a) and in the top of the second layer in the Laguna Salada and Mexicali Valley regions (regions that define the basement of these two basins). Then, we modify the topography and velocity of each layer to adjust the calculated times to the observed ones (reduced time). The starting velocities were derived from plotting the unreduced travel-time curves (observations) against distance. After modeling all the phases observed in the record section of the direct shot (Fig. 3b), we obtained a three-layer structure over a half-space. This model yielded an rms of 0.32 using RAYINVR. Then the relative amplitudes of the synthetic seismograms were computed using the TRAMP routine and were plotted with the PLTSYN routine. Both routines are integrated in the RAYINVR program. The amplitudes of the synthetic seismograms (Figs. 3e and 4e) were compared to the record sections shown in Figures $3 \mathrm{~b}$ and $4 \mathrm{~b}$, and then adjusted. We applied the 
(a)

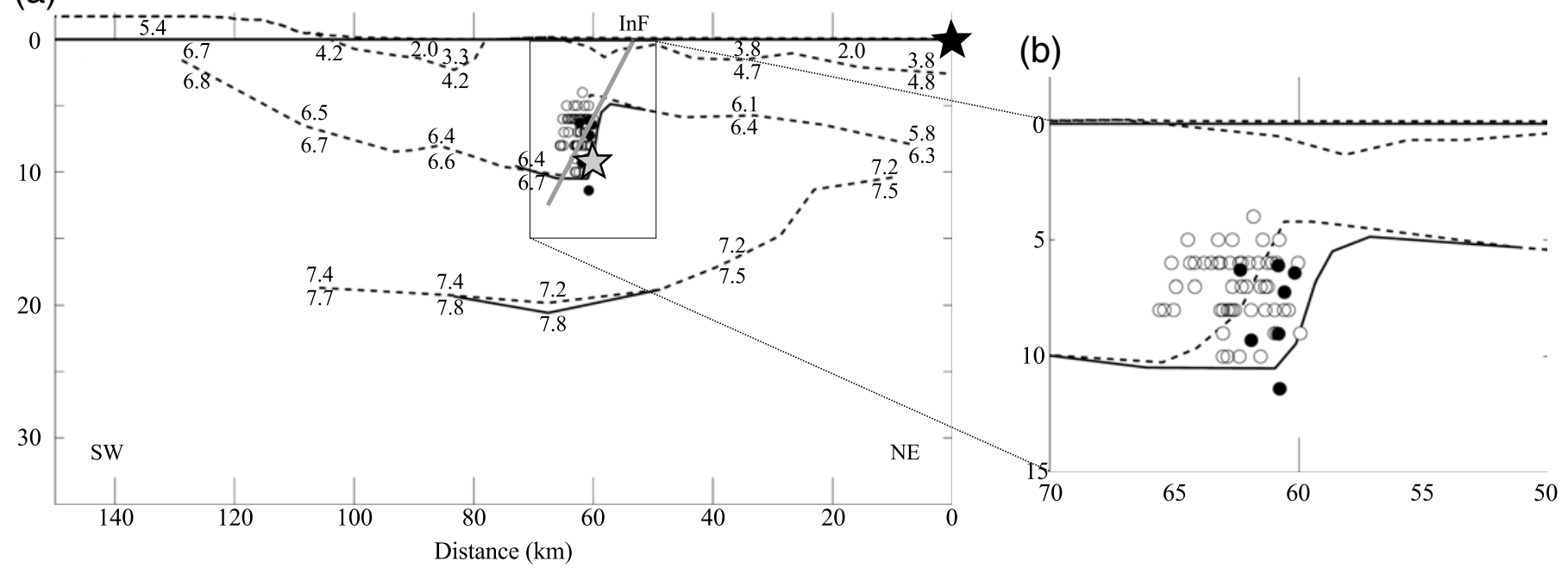

- Figure 5. Crustal velocity models obtained from the direct and reversed source. The models are similar overall (dashed line); however, where they diverge, the dashed line represents the direct-shot model and continuous line the reverse-shot model. In (a), the numbers inside each layer represent the value of the velocity $(\mathrm{km} / \mathrm{s})$ adjacent to the discontinuities of the model, and (b) shows a higher-resolution view of the structure and the projections, to the profile, of the earthquakes selected from the RESNOM database (open circles), and the aftershocks analyzed by Castro et al. (2011; black circles). The gray line is the linear adjustment and projection to the surface of the fault that we interpreted as the Indiviso fault (InF). Black and gray stars are the locations of the direct and reversed shots, respectively.

amplitude constraints (modifying the velocity contrast and gradient of the layers) to reproduce the average behavior of each arrival branch on the basis of the observed changes in intratrace relative amplitudes with distance. After this procedure, the rms travel-time residual of the direct shot modeling dropped to 0.18 . After we had the direct shot model, we used it for the reverse source modeling with the same process described in the Modeling Travel Times and Amplitudes section.

\section{The Results}

Figures $3 \mathrm{c}$ and $4 \mathrm{c}$ show the ray tracing over our direct and reverse shot models, obtained from the records of direct and reversed shots, respectively. The poor coverage in the Laguna Salada area (Fig. 1), due to access problems, was improved (to set only the depth limit of the first layer; see Fig. 5) with information from the following studies: (1) a seismic reflection study by GallardoMata (2013), in which one of the seismic profiles of his study (4965) is parallel and close (10 km distance) to our refraction profile, and (2) a stratigraphic study by Martín-Barajas et al. (2001) that was based on a well $\log$ (ELS-3) made by the Federal Electricity Commission (Comisión Federal de Electricidad [CFE], in Spanish). This well log is located just $3 \mathrm{~km}$ away from the study profile. The location of both the 4965 profile and ELS3 well $\log$ are shown in Figure 1.

Figure 5 a shows the models obtained from the direct shot (direct model, DM) and from the reversed source (reverse model, RM). The valley fill in the Laguna Salada and Mexicali Valley basins was modeled with a first layer, with maximum depths of 2.3 and $2.1 \mathrm{~km}$ and velocities of 1.9 and $2.1 \mathrm{~km} / \mathrm{s}$, respectively (not shown in the figure). In the bottom of the Mexicali Valley and Laguna Salada basins, we have a $P$-wave velocity of $3.8 \mathrm{~km} / \mathrm{s}$ and $3.3 \mathrm{~km} / \mathrm{s}$, respectively. For the basement (second layer), the velocity at the top of the layer is $4.8 \mathrm{~km} / \mathrm{s}$ for the Mexicali Valley and $4.2 \mathrm{~km} / \mathrm{s}$ for the Laguna Salada. Where this basement layer emerges in the El Mayor and Sierra Juárez Mountains, velocity at the top of the layer is $5.4 \mathrm{~km} / \mathrm{s}$ and in its lower part is $6.7 \mathrm{~km} / \mathrm{s}$. Average velocity of this layer is $5.7 \mathrm{~km} / \mathrm{s}$. This layer has a maximum depth of $10.3 \mathrm{~km}$. Maximum depth of the third layer of the model goes from $10.5 \mathrm{~km}$ (at Mexicali Valley), to a maximum depth of $20 \mathrm{~km}$ (in the direction of the El Mayor and Sierra Juárez Mountains). This layer has an average velocity of $6.9 \mathrm{~km} / \mathrm{s}$. The bottom part of the third layer has an average velocity of $7.2 \mathrm{~km} / \mathrm{s}$, and the average velocity for the half-space (beneath the third layer) is $7.7 \mathrm{~km} / \mathrm{s}$.

From Figure 5a, we observe that the DM and the RM have the same topography and velocities except at distances between 50 and $85 \mathrm{~km}$ of the profile. In this section of the model, we can see the following:

- There is a structure between the second and the third layer of our proposed models, at the interface located around $60 \mathrm{~km}$ of distance. In this region, the RM is separated from the DM by $2.85 \mathrm{~km}$ in the northeast direction.

- The maximum difference between the RM and the DM, in the interface that divides the third layer from the halfspace, is $1.45 \mathrm{~km}$.

- The differences in the velocity values in some points of the two models are less than $0.1 \mathrm{~km} / \mathrm{s}$.

One of the features seen in the reduced-time record section of the direct shot (Fig. 3b) is that at the first $30 \mathrm{~km}$ of distance the seismograms show a delay and tend to stabilize, but from 40 to $80 \mathrm{~km}$ the arrivals arrive faster. The increase of velocity of these arrivals is explained in terms of the model 


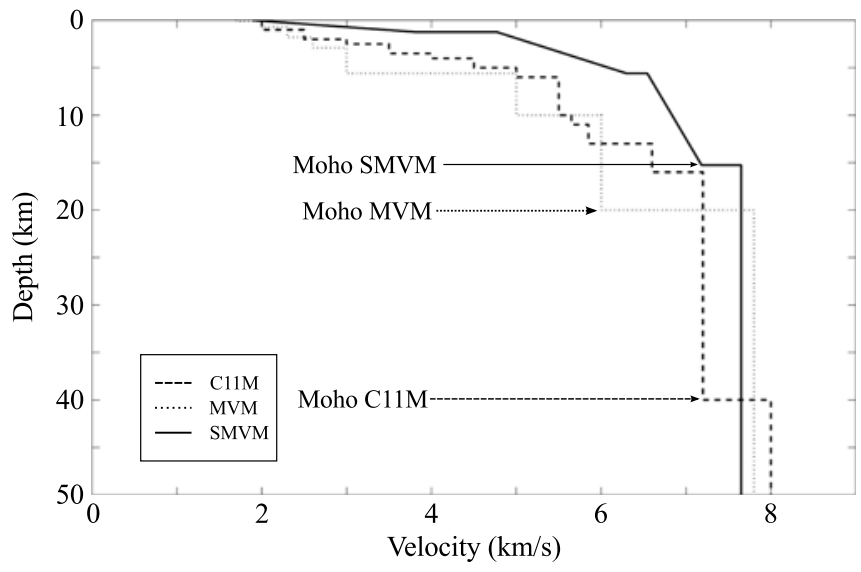

A Figure 6. Comparison of the previous crustal and upper-mantle velocity models for the Mexicali Valley (MVM and C11M) against our new model for the southern Mexicali Valley (SMVM). Main differences are the high $P$-wave velocity and the shallow depth of the Moho discontinuity. The $P$-wave velocities for the SMVM are up to $1.5 \mathrm{~km} / \mathrm{s}$ higher than the velocities for the other two models, for depths $<20 \mathrm{~km}$. The depth of the Moho discontinuity (indicated by arrows for each model) is shallow for SMVM (15.2 km) compared with the values proposed in the MVM and C11M.

that we propose (Fig. 5a). As the distance increases to $85 \mathrm{~km}$ the arrivals again arrive later, and then the trend of $P$ arrivals appears earlier to the end of the profile.

\section{DISCUSSION}

\section{Velocity Structure Model}

We interpreted the differences between the DM and the RM due to the $3.5 \mathrm{~km}$ north-south separation of the earthquake used as reversed source. The offline location of the reversed source from the profile adds a $3 \mathrm{D}$ effect that causes the differences between the two models. This is because the rays have to travel as much as $3.5 \mathrm{~km}$ farther from the hypocenter to the stations of the profile. In the comparison of the models (Fig. 5a), it is clear that at larger distances (more than $15 \mathrm{~km}$ from the reversed source) the models are the same. This is because at larger distances the nonalignment effect of the reversed source to the profile has no effect.

We took a section of the model that runs from 0 to $50 \mathrm{~km}$ distance along the profile (corresponding to the southern Mexicali Valley) and determined an average velocity structure model of three flat layers (southern Mexicali Valley model, SMVM). We obtained this model by averaging depths and velocity gradient of the layers of our original model. A comparison of the SMVM with the velocity models commonly used in southern Mexicali Valley (the MVM and the C11M) is shown in Figure 6 and Table 3. The SMVM has 3 layers, whereas the MVM has 7 layers and the C11M has 12 layers. Figure 6 shows that velocities of the SMVM are $\sim 1.5 \mathrm{~km} / \mathrm{s}$ higher than those of MVM for depths $<20 \mathrm{~km}$ and $\sim 0.2 \mathrm{~km} / \mathrm{s}$ slower for depths greater than $20 \mathrm{~km}$. Comparing the SMVM with C11M, we see that for depths shallower than $5.6 \mathrm{~km}$, the difference in velocity is less than $1 \mathrm{~km} / \mathrm{s}$. However, for depths between 5.6 and $15.0 \mathrm{~km}$, the SMVM shows velocities higher by more than $1 \mathrm{~km} / \mathrm{s}$. For depths below $15.3 \mathrm{~km}$, the SMVM has a velocity $\sim 0.5 \mathrm{~km} / \mathrm{s}$ higher than the C11M. The SMVM shows the Moho discontinuity at $15 \mathrm{~km}, 5 \mathrm{~km}$ shallower than in MVM and $25 \mathrm{~km}$ shallower than in C11M. The westward dip of the Moho discontinuity, shown in DM and RM (Fig. 5a) under Mexicali Valley and Laguna Salada, is a regional feature; however, there is little to no change in the topography. A receiver function study by Lewis et al. (2001), done $\sim 140 \mathrm{~km}$ south of our study area, suggested that the change in the Moho depth, from west to

\begin{tabular}{|c|c|c|c|c|c|}
\hline \multicolumn{6}{|c|}{$\begin{array}{c}\text { Table } 3 \\
\text { List of Values Presented in Figure } 6 \text { for the Velocity Models Used in the Area }\end{array}$} \\
\hline \multicolumn{6}{|c|}{ Models } \\
\hline \multicolumn{2}{|r|}{ MVM } & \multicolumn{2}{|r|}{ C11M } & \multicolumn{2}{|r|}{ SMVM } \\
\hline Depth (km) & $P$-Wave Velocity $(\mathrm{km} / \mathrm{s})$ & Depth (km) & $P$-Wave Velocity $(\mathrm{km} / \mathrm{s})$ & Depth (km) & $P$-wave Velocity $(\mathrm{km} / \mathrm{s})$ \\
\hline $0.00-0.10$ & 1.70 & $0.00-1.00$ & 2.00 & $0.00-1.23$ & $1.90-3.81$ \\
\hline $0.10-0.70$ & 2.00 & $1.00-2.00$ & 2.50 & $1.23-5.60$ & $4.77-6.30$ \\
\hline $0.70-1.80$ & 2.30 & $2.00-2.50$ & 3.00 & $5.60-15.25$ & $6.54-7.18$ \\
\hline $1.80-2.90$ & 2.60 & $2.50-3.50$ & 3.50 & 15.27 & 7.65 \\
\hline $2.90-5.60$ & 3.00 & $3.50-4.00$ & 4.00 & - & - \\
\hline $5.60-10.00$ & 5.00 & $4.00-5.00$ & 4.50 & - & - \\
\hline $10.00-20.00$ & 6.00 & $5.00-6.00$ & 5.00 & - & - \\
\hline 20.00 & 7.80 & $6.00-10.00$ & 5.50 & - & - \\
\hline- & - & $10.00-11.00$ & 5.65 & - & - \\
\hline- & - & $11.00-13.00$ & 5.85 & - & - \\
\hline - & - & $13.0-16.00$ & 6.60 & - & - \\
\hline - & - & $16.00-40.00$ & 7.20 & - & - \\
\hline - & - & $40.00-$ & 8.0 & - & - \\
\hline
\end{tabular}




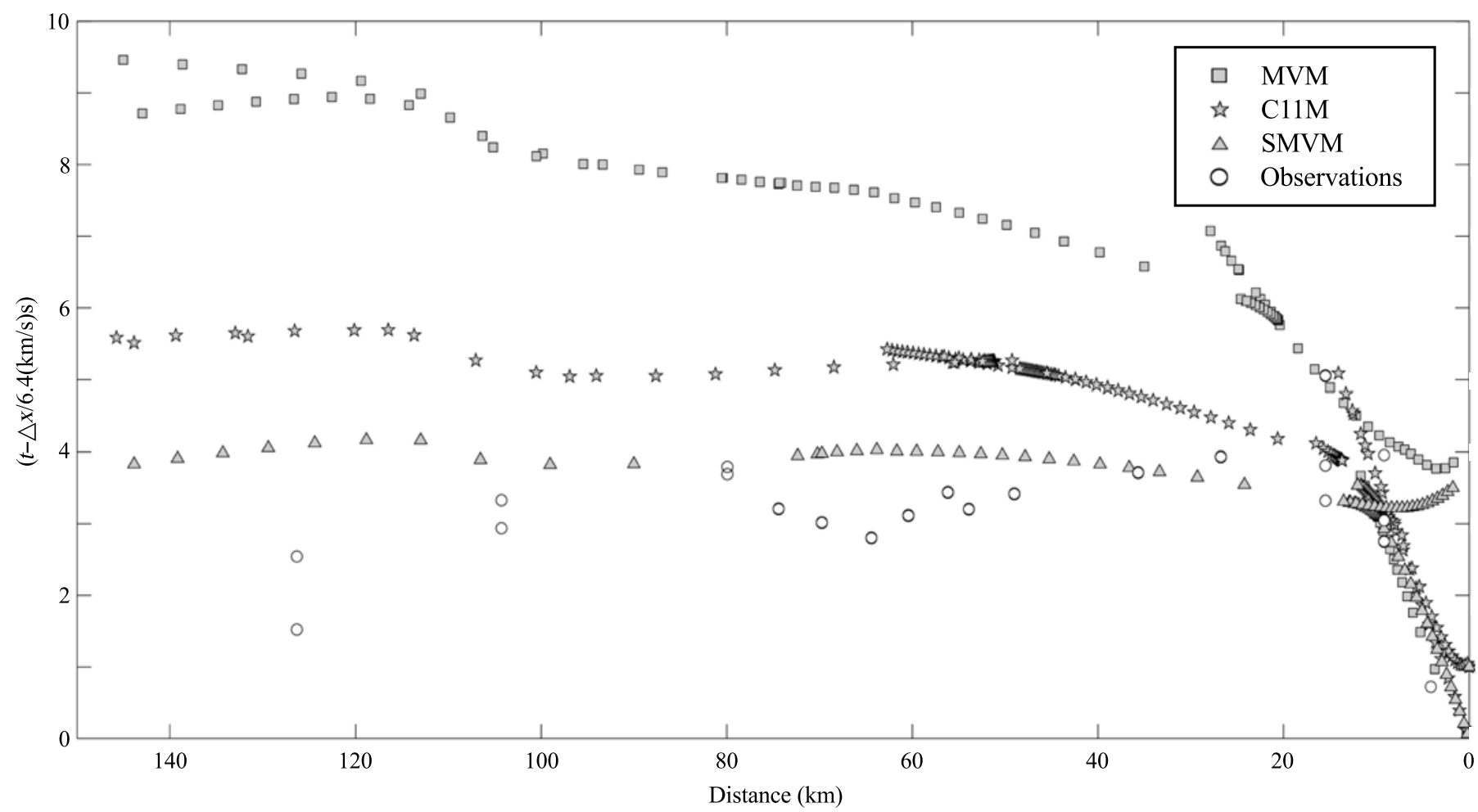

A Figure 7. The observed arrival times of the explosion across the refraction profile with reduced time and the calculated arrival times using the MVM (Fabriol and Munguía, 1995) and the C11M (Castro et al., 2011). The figure also shows the arrival times computed using a flat-layer version of our model (SMVM). This last model is the one that best fits the observations in most of the distance range.

east in northern Baja California, is due to the extensional deformation of the lower crust in response to the adjacent rifting of the Gulf Extensional Province.

In Figure 7, we plot the observed reduced-time arrivals of the explosion and the calculated reduced-time arrivals using three different models along with the topography of the surface (Fig. 3a). These models are the SMVM, the MVM, and the C11M. In the figure, for distances less than $20 \mathrm{~km}$, the calculated arrival times for the three models are well fit to observed arrival times. This behavior changes when the distance increases. For instance, in the calculated arrival times using the three models, for distances greater than $110 \mathrm{~km}$, a delay in the calculated data is observed (Fig. 7), due to the effect of the beginning of the Sierra Juárez mountain range (Fig. 3a). The modeled arrival times for the MVM present the $P n$ arrivals for distances greater than $100 \mathrm{~km}$ in the profile. From Figure 7, we can see that the calculated arrival times from the SMVM flatlayered model are the best fit to the observations. The differences in the calculated arrival time and the observed data (Fig. 7) for the southern Mexicali Valley and Laguna Salada are, on average, $<1.0 \mathrm{~s},>1.5 \mathrm{~s}$, and $>5.0 \mathrm{~s}$ for the SMVM, the $\mathrm{C} 11 \mathrm{M}$, and the MVM, respectively.

One of the main features shown in our model is the structure at $\sim 60 \mathrm{~km}$ southwest from the beginning of the profile, which is the boundary between the second and the third layers (Fig. 5b). We modeled this structure by means of a line (gray line in Fig. 5a) and interpreted it as a fault plane (striking perpendicular to the refraction profile). When we extrapolate this line to the surface (white squares in Fig. 8a,b), we get a plane dipping $57^{\circ} \mathrm{SW}$. We interpreted this structure as the Indiviso fault. Further details regarding the validation of this interpretation are discussed next.

\section{Seismicity Near the Profile}

To find additional information to associate the structure to the Indiviso fault, we searched earthquakes $\mathrm{M}>3.0$ from 1 April 2010 to 25 November 2012 in the RESNOM database. Our search area, the rectangle shown in Figure 8a (between $32^{\circ} 30^{\prime},-115^{\circ} 30^{\prime}$ and $\sim 32^{\circ},-115^{\circ}$ ), yielded 147 events. In addition, we included 255 hypocenters of the survey performed by Castro et al. (2011) of the aftershocks of the 4 April 2010 $M_{\mathrm{w}} 7.2 \mathrm{El}$ Mayor-Cucapah earthquake. The authors located the selected earthquakes from the first two days of arrival times measured at 14 temporary stations, which functioned from 6 April to 14 May 2010. A good azimuthal coverage along the rupture zone and short epicentral distances was reported in their study. These earthquakes and those from RESNOM are illustrated in Figure 8a with black and white circles, respectively.

Earthquakes at distances less than $1 \mathrm{~km}$ from the profile (Fig. 8a) were selected and projected normally to the refraction profile plane (Fig. 5a,b). With this selection, we had 58 earthquakes reported by RESNOM and 9 earthquakes reported by Castro et al. (2011). In Figure 5a,b, it is evident that the hypocenters when projected along the profile are concentrated in the reported structure, which is in the depth range of the seismogenic zone reported by Castro et al. (2011). The projection 
(a)

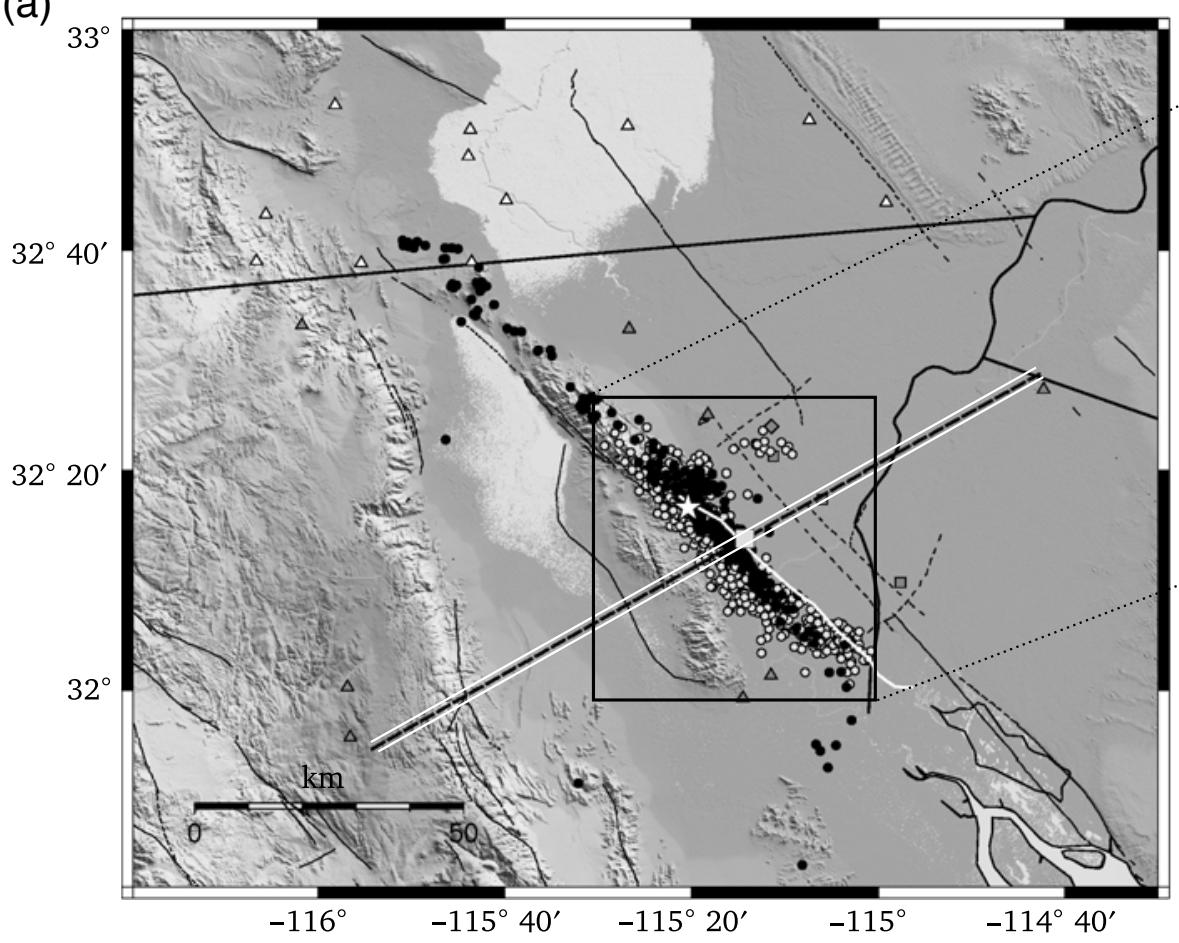

(b)

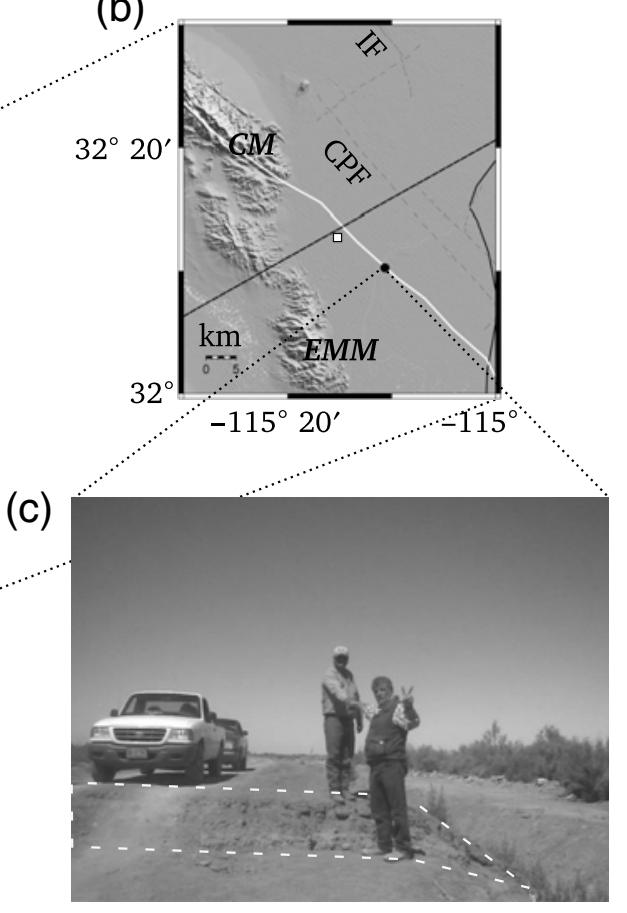

A Figure 8. (a) The aftershock distribution of the $M_{\mathrm{w}} 7.2 \mathrm{El}$ Mayor-Cucapah earthquake (white star), along with the Indiviso fault trace. The white circles represent the $M>3.0$ earthquakes reported by RESNOM (from 1 April 2010 to 25 November 2012), and the black circles represent the epicenters located by Castro et al. (2011). Thin white line is the Cucapah-Indiviso fault proposed by González-García et al. (2010). The black dashed line indicates the refraction profile; white straight lines are drawn $\pm 1 \mathrm{~km}$ distance from the profile limits. (b) Inset showing the projection to the surface of the structure interpreted as the Indiviso fault (white square) and surface evidence of this fault (black circle). (c) Photograph by González-García (personal comm., 2013), which was taken looking eastward at a site named Canal Barrote, south of Mexicali Valley. The photo shows the vertical displacement $(30 \mathrm{~cm})$ of a dirt road (fault scarp) due to the rupture of the Indiviso fault (mapped after the occurrence of El Mayor-Cucapah earthquake).

of this structure to the surface is $\sim 1.9 \mathrm{~km}$ away from the fault trace proposed by González-Garcia et al. (2010; Fig. 8b).

\section{Indiviso Fault Validation}

Using analysis of ALOS PALSAR and Landsat imagery, González-García et al. (2010) found the Indiviso fault, which also ruptured during the $M_{\mathrm{w}} 7.2 \mathrm{El}$ Mayor-Cucapah earthquake. These authors described the rupture due to this earthquake in two sections (1) northwest of the epicenter (rupture of Pescadores and Borrego faults with dominant right lateral strike-slip motion, and a northeast-side down component of dip-slip motion), and (2) southeast of the epicenter (rupture of Indiviso fault having a dominant right-lateral strike-slip motion, with the southwest side showing a component of downward dipslip motion). Figure 8a,b shows the trace of the faults. The dip angle of the Indiviso fault $\left(60^{\circ}\right.$ reported by Fialko et al., 2010, at $25 \mathrm{~km}$ southeast of the white square of Fig. $8 \mathrm{a}$ ) is close to the $57^{\circ}$ calculated for the structure reported in this study. A photograph (Gonzalez-Ortega, personal comm., 2013) taken in mid-April 2010 (right after the $M_{\mathrm{w}} 7.2$ earthquake; Fig. 8c) shows that the dirt road was displaced vertically with the west side dropped by $\sim 45 \mathrm{~cm}$. This photograph shows the clearest image of the rupture at the surface of the Indiviso fault. In agreement with this field observation, after modeling displacements derived from Global Positioning System and Interferometric Synthetic Aperture Radar observations, González-Ortega et al. (2014) found a postseismic fault slip of $\sim 10-40 \mathrm{~cm}$ on the Indiviso fault.

By analyzing the seismicity in the area of study (Fig. 8a) and projection of hypocenters over the proposed velocity model (Figs. 5a and b), it is clear that the described structure is associated with the seismogenic zone. By extrapolating this position of the structure to the surface (Fig. $8 \mathrm{~b}$ ) and plotting it along with the Cucapah-Indiviso fault trace (proposed by González-García et al., 2010), we propose that the modeled structure is the Indiviso fault.

\section{CONCLUSIONS}

We deployed 16 three-component seismic stations spaced $\sim 6 \mathrm{~km}$ apart to record an explosion performed in southern Arizona that worked as a direct shot. Because we did not have a proper controlled source (explosion), we used a well-located earthquake as a reversed source.

Using these shots, we modeled the travel time and normalized amplitudes of $P$ waves $(P g$ and $P n)$ using asymptotic ray theory. Although we did not have a large set of seismograms in 
both direct and reversed shots, our data support the principal features that we modeled. We found a three-flat-layer velocity structure model for the southern Mexicali Valley. Average velocities of these layers are $2.9,5.6$, and $6.9 \mathrm{~km} / \mathrm{s}$ on layer boundaries at depths of 1.23 and $5.60 \mathrm{~km}$. We supplemented our refraction data with results of studies by Gallardo-Mata (2013) and Martín-Barajas et al. (2001) to model the Laguna Salada basin. On the basis of modeling the $P n$ arrivals, we propose that the Moho is at $15 \mathrm{~km}$ depth under the Mexicali Valley basin, reaching a depth of $19 \mathrm{~km}$ under Laguna Salada basin. We associate this depth variation to the extensional deformation of the lower crust due to the rifting of the Gulf Extensional Province. We propose a velocity of $7.7 \mathrm{~km} / \mathrm{s}$ for the mantle in the southern Mexicali Valley.

On the basis of our model, we explain the effect of the early arrival of the $P$ waves, at $40-80 \mathrm{~km}$ in the refraction profile, probably due to the presence of El Mayor Mountain. This basement block separates the Mexicali Valley and Laguna Salada basins. The relief of this mountain contributes to the difference in the velocity of the seismic signal relative to the velocity of the sediments $(2.5 \mathrm{~km} / \mathrm{s}$ slower than the modeled emergent basement) of the two basins.

Our new velocity model has velocities $\sim 1.0 \mathrm{~km} / \mathrm{s}$ higher than velocities of previous models used in the region. A flatlayer version of our velocity model is the one that best fits the arrival time data of the explosion in the reduced-time plot. In contrast, the previous velocity models do not fit these data. These models show up to $5.0 \mathrm{~s}$ of residual times (calculated minus observed). This comparison supports the validity of our proposed model for southern Mexicali Valley.

We conclude that the structure (step of the boundary), seen between the second and third layers at around $60 \mathrm{~km}$ southwest from the beginning of the profile, is the Indiviso fault. Our conclusion is based on the analysis of seismicity around the profile ( $\pm 1 \mathrm{~km}$ of separation) and then projected to the model. Also, by adjusting a line to the structure, we found a dip of $57^{\circ}$ in the southwest direction, which is close to the $60^{\circ}$ dip reported in a previous study by Fialko et al. (2010). The extrapolation of this line to the surface is $1.9 \mathrm{~km}$ away from the Cucapah-Indiviso fault, reported by these authors. Both analyses gave us elements to identify the Indiviso fault, the existence of which was unrecognized before 2010. Results detailed in this paper contribute to the characterization of the fault. $\mathbf{z}$

\section{ACKNOWLEDGMENTS}

This project was the first of a bigger project designed to improve the estimation of the crustal model for the northern region of Baja California. The Mexican National Council Science and Technology (Consejo Nacional de Ciencia y Tecnología [CONACYT], in Spanish) provided financial support for this project (CB-2009-133019 SEP-CONACYT). J. Stock's participation was supported by National Science Foundation (NSF) Grant OCE-0742253. This work was performed using the facilities of Centro de Investigación Científica y de Educació n Superior de Ensenada (CICESE). José Acosta pro- vided us the $2 \mathrm{~Hz}$ seismic stations deployed to record the explosion, and Gustavo Arellano and Euclides Ruíz provided the technical support for the SARA (http://www.sara.pg.it/scat .asp?idscat=17; last accessed October 2014) instrumentation. We acknowledge Luis Orozco, Oscar Gálvez, Francisco Méndez, Francisco Farfán, and Orlando Granados for their help in the installation of the instrumentation along the profile. Sergio Arregui provided the main script that we used for generating the maps using the Generic Mapping Tools (www.soest.hawaii. edu/gmt, last accessed October 2014; Wessel and Smith, 2009) software. We thank the RESNOM staff for the assistance in data accessibility (wave forms and location files) of the earthquakes used in this work. The comments and suggestions provided by Editor-in-Chief Zhigang Peng, Walter D. Mooney, and an anonymous reviewer substantially improved the content of this paper.

\section{REFERENCES}

Angelier, J., B. Colletta, J. Chorowick, L. Ortlieb, and C. Rangin (1981). Fault tectonics of the Baja California peninsula and the opening of the Sea of Cortés, Mexico, J. Struct. Geol. 3, no. 4, 347-357.

Armstrong, P. A. (2010). Timing and controls on late Quaternary landscape development along the eastern Sierra El Mayor range front in northern Baja California, Mexico, Geomorphology 114, no. 3, 415.

Axen, G. J., and J. M. Fletcher (1998). Late Miocene-Pleistocene extensional faulting, northern Gulf of California, México, and Salton trough, California, Int. Geol. Rev. 40, no. 3, 217-244.

Castro, R. R., J. G. Acosta, V. M. Wong, A. Perez-Verti, A. Mendoza, and L. Inzunza (2011). Location of aftershocks of the 4 April 2010 $M_{\mathrm{w}} 7.2$ El Mayor-Cucapah earthquake of Baja California, Mexico, Bull. Seismol. Soc. Am. 101, no. 6, 3071-3080.

Contreras, J., A. Martín-Barajas, and J. C. Helguera (2005). Subsidence of the Laguna Salada basin, northeastern Baja California, Mexico, inferred from Milankovitch climate changes, Geof. Int. 44, no. 1, 103-111.

Fabriol, H., and L. Munguía (1995). Seismic activity at the Cerro Prieto geothermal area (México) from August 1994 to December 1995, and its relationship with tectonics and fluid exploitation, Geophys. Res. Lett. 24, no. 14, 1807-1810.

Fialko, Y., A. González, J. González, S. Barbot, S. Leprince, D. Sandwell, and D. Agnew (2010). Static rupture model of the $2010 M_{\mathrm{w}} 7.2 \mathrm{El}$ Mayor-Cucapah earthquake from ALOS, ENVISAT, SPOT and GPS data, American Geophysical Union, Fall Meeting, Abstract T53B-2125, San Francisco, California, http://igppweb.ucsd.edu/ fialko/baja.html (last accessed October 2013).

Fletcher, J. M., and R. M. Spelz (2009). Patterns of Quaternary deformation and rupture propagation associated with an active low-angle normal fault, Laguna Salada, Mexico: Evidence of a rolling hinge? Geosphere 5, no. 4, 385-407.

Fletcher, J. M., O. J. Teran, T. K. Rockwell, M. E. Oskin, K. W. Hudnut, K. J. Mueller, R. M. Spelz, S. O. Akciz, E. Masana, G. Faneros, E. J. Fielding, S. Leprince, A. E. Morelan, J. M. Stock, D. K. Lynch, A. J. Elliott, P. Gold, J. Liu-Zeng, A. González-Ortega, A. HinojosaCorona, and J. González-García (2014). Assembly of a large earthquake from a complex fault system: Surface rupture kinematics of the 4 April 2010 El Mayor-Cucapah (Mexico) $M_{\mathrm{w}} 7.2$ earthquake, Geosphere 10, no. 3, doi: 10.1130/GES00933.1.

Fuis, G. S., W. D. Mooney, J. H. Healy, G. A. McMechan, and W. J. Lutter (1984). A seismic refraction survey of the Imperial Valley region, California, J. Geophys. Res. 89, 1165-1189.

Gallardo-Mata, C. (2013). Sismica de reflexión en Laguna Salada, Baja California, México, Master's Thesis, Centro de Investigación 
Científica y de Educación Superior de Ensenada. Baja California, México, 96 pp.

García-Abdeslem, J., J. M. Espinoza-Cardeña, L. Munguía, V. M. Wong, and J. Ramírez-Hernández (2001). Crustal structure from 2-D gravity and magnetic data modeling, magnetic power spectrum inversion, and seismotectonics in the Laguna Salada basin, northern Baja California, Mexico, Geofis. Int. 40, no. 2, 67-85.

González-García, J. J., A. González-Ortega, Y. Buck, Y. Fialko, E. Fielding, J. M. Fletcher, J. Galetzka, K. W. Hudnut, L. Munguía, S. Nelson, T. K. Rockwell, D. Sandwell, and J. Stock (2010). Seismotectonics of the 2010 El Mayor Cucapah-Indiviso earthquake and its relation to seismic hazard in Southern California, Eos Trans. AGU (Fall Meet.), Abstract T53B 2117.

Gonzalez-Ortega, A., D. Sandwell, Y. Fialko, A. Nava-Pichardo, J. M. Fletcher, J. Gonzalez-Garcia, B. Lipovsky, M. Floyd, and G. Funning (2014). El Mayor-Cucapah ( $M_{\mathrm{w}}$ 7.2) earthquake: Early near-field postseismic deformation from InSAR and GPS observations, J. Geophys. Res. doi: 10.1002/2013JB010193.

Havskov, J., and L. Ottemöller (1999). SeisAn earthquake analysis software, Seismol. Res. Lett. 70, no. 5, 532-534.

Henry, C. D. (1989). Late Cenozoic basin and range structure in western México adjacent to the Gulf of California, Geol. Soc. Am. Bull. 101, $1147-1156$.

Lomnitz, C., C. R. Mooser, C. R. Allen, J. N. Brune, and W. Thatcher (1970). Seismicity and tectonics of the northern Gulf of California region, México, preliminary results, Geofis. Int. 10, 37-48.

Lewis, J. L., S. M. Day, H. Magistrale, R. R. Castro, L. Astiz, C. Rebollar, J. Eakins, F. y. Vernon, and J. N. Brune (2001). Crustal thickness of the Peninsular Ranges and Gulf Extensional Province, in the Californias, J. Geophys. Res. 106, 13,599-13,611.

Martín-Barajas, A., S. Vázquez-Hernández, A. L. Carreño, J. Helenes, F. Suárez-Vidal, and J. Alvarado-Rosales (2001). Late Neogene stratigraphy and tectonic control on facies evolution in the Laguna Salada basin, northern Baja California, Mexico, Sediment. Geol. 144, 5-35.

McMechan, G. A., and W. D. Mooney (1980). Asymptotic ray theory and synthetic seismograms for laterally varying structures: Theory and application to the Imperial Valley, California, Bull. Seismol. Soc. Am. 70, 2021-2035.

Nava, F. A., and J. N. Brune (1982). An earthquake-explosion reversed refraction line in the Peninsular Ranges of southern California and Baja California, Bull. Seismol. Soc. Am. 72, 1195-1206.

Oskin, M. E., J. R. Arrowsmith, A. Hinojosa-Corona, A. J. Elliott, J. M. Fletcher, E. J. Fielding, P. O. Gold, J. J. González-García, K. W. Hudnut, J. Liu-Zeng, and O. J. Terán (2012). Near-field deformation from the El Mayor-Cucapah earthquake revealed by differential LiDAR, Science 335, 702-705.

Ottemöller, L., and J. Havskov (1999). SeisNet: A general purpose virtual seismic network, Seismol. Res. Lett. 70, no. 5, 522-528.

Pelayo, A., L. A. Razo, N. L. C. A. Gutiérrez, G. F. Arellano, J. M. Espinoza, and J. L. Quijano (1991). Main geothermal fields of Mexico: Cerro Prieto geothermal field, Baja California, Geological Society of America, The Geology of North America, Vol. P-3, Economic Geology, México, 23-58.

Plattner, C., R. Malservisi, T. H. Dixon, G. F. Sella, P. Lafemina, J. M. Fletcher, and F. Suarez-Vidal (2007). New constraints on relative motion between the Pacific plate and Baja California microplate (Mexico) from GPS measurements, Geophys. J. Int. 170, 1373-1380.

Rose, E. J., G. S. Fuis, J. M. Stock, J. A. Hole, A. M. Kell, G. Kent, N. W. Driscoll, S. Crum, M. Goldman, A. M. Reusch, L. Han, R. R. Sickler, R. D. Catchings, M. J. Rymer, C. J. Criley, D. S. Scheirer, S. M. Skinner, C. J. Slayday-Criley, J. M. Murphy, E. G. Jensen, R. McClearn, A. J. Ferguson, L. A. Butcher, M. A. Gardner, I. Emmons, C. L. Loughran, J. R. Svitek, P. C. Bastien, J. A. Cotton, D. S. Croker, A. J. Harding, J. M. Babcock, S. H. Harder, and C. M. Rosa (2013). Borehole-explosion and air-gun data acquired in the 2011 Salton Seismic Imaging Project (SSIP), southern California-
Description of the survey, U.S. Geol. Surv. Open-File Rept. 20131172, 84 pp., doi: 10.3133/ofr20131172.

Seiler, C., J. M. Fletcher, M. C. Quigley, A. J. W. Gleadow, and B. P. Khon (2010). Neogene structural evolution of the Sierra San Felipe, Baja California: Evidence for proto-gulf transtension in the Gulf Extensional Province? Tectonophysics 488, 87-109.

Song, J. L., and U. ten Brink (2005). RayGUI 2.0-A graphical user interface for interactive forward and inversion ray-tracing, U.S. Geol. Surv. Open-File Rept. 2004-1426, 33.

Spelz-Madero, R. M., J. M. Fletcher, O. Lewis, and M. W. Caffee (2008). Quaternary alluvial-fan development, climate and morphologic dating of fault scarps in Laguna Salada, Baja California, Mexico, Geomorphology 102, nos. 3/4, 578-594.

Stock, J. M., A. Martín-Barajas, F. Suárez-Vidal, and M. M. Miller (1991). Miocene to Holocene extensional tectonics and volcanic stratigraphy of NE Baja California, Mexico, in Geological Excursions in Southern California and Mexico, Michael J. Walawender and B. Hanan (Editors), San Diego State University, Department of Geological Sciences, San Diego, California, 44-67.

Suárez-Vidal, F., L. Munguía, M. González-Escobar, J. J. González-García, and E. Glowacka (2007). Surface rupture of the Morelia fault near the Cerro Prieto geothermal field, Mexicali, Baja California, Mexico, during the $M_{\mathrm{w}} 5.4$ earthquake of May 24, 2006, Seismol. Res. Lett. 78, no. 3, 394-399.

Suárez-Vidal, F., R. Mendoza-Borunda, L. M. Nafarrete-Zamarripa, J. Ramírez, and E. Glowacka (2008). Shape and dimensions of the Cerro Prieto pull-apart basin, Mexicali, Baja California, Mexico, based on the regional seismic record and surface structures, Int. Geol. Rev. 50, 636-649.

Wei, S., E. Fielding, S. Leprince, A. Sladen, J.-P. Avouac, D. Helmberger, E. Hauksson, R. Chu, M. Simons, K. Hudnut, T. Herring, and R. Briggs (2011). Superficial simplicity of the 2010 El Mayor-Cucapah earthquake of Baja California in Mexico, Nat. Geosci. 4, no. 9, 615-618.

Wessel, P., and W. H. F. Smith (2009). The Generic Mapping Tools (GMT) version 4.5.0 Technical Reference \& Cookbook, SOEST/ NOAA, available at http://gmt.soest.hawaii.edu (last accessed January 2014).

Zelt, C. A., and R. M. Ellis (1998). Practical and efficient ray tracing in two-dimensional media for rapid traveltime and amplitude forward modeling, Can. J. Explor. Geophys. 24, 16-31.

Zelt, C. A., and R. B. Smith (1992). Seismic traveltime inversion for 2-D crustal velocity structure, Geophys. J. Int. 108, 16-34.

Erik E. Ramirez-Ramos Antonio Vidal-Villegas Antonio González-Fernández División Ciencias de La Tierra

Centro de Investigación Cientifica y de Educación Superior de Ensenada (CICESE)

Carretera Tijuana-Ensenada No. 3918 Zona Playitas Ensenada Baja California, 22860 Mexico eramirez@cicese.edu.mx vidalv@cicese.mx mindundi@cicese.mx

Joann M. Stock Seismological Laboratory Division of Geological and Planetary Sciences California Institute of Technology Pasadena, California 91125 U.S.A. jstock@gps.caltech.edu

Published Online 5 November 2014 